\title{
DIFFERENTIAL EXPRESSION ANALYSIS OF OIL PALM FATTY ACID BIOSYNTHETIC ENZYMES WITH GEL-FREE QUANTITATIVE PROTEOMICS
}

\section{BENJAMIN YII CHUNG, LAU*; JAMES D MORTON ${ }^{\star *}$; SANTANU DEB-CHOUDHURY*; STEFAN CLERENS ${ }^{*} ;$ JOLON M DYER ${ }^{*}$ and UMI SALAMAH RAMLI*}

\begin{abstract}
The control mechanisms of de novo fatty acid biosynthesis continue to intrigue, particularly at protein level. The cross talk between transcriptional and metabolic regulatory networks remains undefined. In order to understand the metabolic factors affecting oleic acid biosynthesis in Elaeis guineensis var. tenera (oil palm), two-dimensional liquid chromatography-tandem mass spectrometry (2DLC-MS/MS) was attempted to capture the main fatty acid biosynthetic enzymes involved in oleic acid production. These enzymes were extracted from the chromoplast of low and high oleic mesocarps of $20^{\text {th }}$ week after anthesis. Chromoplast proteins were separated using offline 2DLC for mass spectrometric analysis. Two subunits of acetyl-CoA carboxylase, $\beta$-ketoacyl-acyl carrier protein (ACP) reductase, $\beta$-hydroxyacyl-ACP dehydrogenase, 3-enoyl$A C P$ reductase, $\beta$-ketoacyl-ACP synthase and stearoyl-ACP desaturase were identified. The relative expression of these fatty acid biosynthetic enzymes was determined using isobaric tags labelling. Initial assessment revealed that $\beta$-hydroxyacyl-ACP dehydrogenase and $\beta$-ketoacyl-ACP synthase were present in a higher abundance in the high oleic acid mesocarps while the accumulation of 3-enoyl-ACP reductase was lower relative to the other fatty acid biosynthetic enzymes investigated. The existence of other differentially expressed metabolic enzymes suggests that the control mechanism of fatty acid production, in particular oleic acid, might involve more than just the main fatty acid biosynthetic enzymes.
\end{abstract}

Keywords: protein expression, fatty acid biosynthesis, proteomics.

Date received: 27 September 2016; Sent for revision: 27 September 2016; Received in final form: 14 December 2016; Accepted: 13 January 2017.

\section{INTRODUCTION}

Oil palm (Elaeis guineensis Jacq.) is a highly valuable economic crop in Malaysia and is the world's highest yielding oil-bearing crop (Parveez et al., 2015; Singh et al., 2013b). Malaysian plantations produce $3.5 \mathrm{t}$ of versatile and nutritious palm oil per hectare annually (Kirkland, 2011). Over the past decade, global demand for vegetable oils has increased at more than 5\% per year (McFerron, 2013). Due to

** Malaysian Palm Oil Board, 6 Persiaran Institusi, Bandar Baru Bangi, 43000 Kajang, Selangor, Malaysia. E-mail: benjamin@mpob.gov.my

** Department of Wine, Food and Molecular Biosciences, Lincoln University, Lincon 7647, New Zealand.

* AgResearch Lincoln Research Centre, Cnr Springs Rd and Gerald Street, Christchurch, New Zealand. major challenges faced by the oil palm industry, in particular the limited land resources and stagnant yield, it is increasingly crucial to raise the yield of oil palm per unit area and to improve its oil quality at a more rapid rate compared to current breeding practice (Parveez et al., 2010). Commercially refined palm oil from fruit mesocarp contains predominantly palmitic acid (44\%), oleic acid (39\%) and stearic acid (5\%) (Dauqan et al., 2011; Sundram et al., 2003; Sundram, 2000). Genetic engineering has been used to generate transgenic oil palms containing more high-value fatty acids to boost sustainability (Parveez et al., 2015). Biochemical studies of lipid biosynthetic pathway revealed significant flux control in the fatty acid biosynthesis over lipid assembly and the results also suggested that manipulation of a single enzyme step would 
not affect the product yield appreciably (Ramli et al., 2002b). Therefore, understanding the mechanism of fatty acid production in oil palm fruit is essential before any work to increase the content of targeted unsaturated fatty acids through genome editing technologies or metabolic engineering (Maeder and Gersbach, 2016; Thelen and Ohlrogge, 2002a; Schultz and Ohlrogge, 2001).

There has been an on-going interest in understanding the mechanism of oil palm lipid biosynthesis using multiple omics approaches including transcriptomics and proteomics. Recently, transcriptomes of the oil palm mesocarp have been explored to understand the regulatory mechanism of fatty acid production (Singh et al., 2013a, b). These studies have revealed that transcripts of fatty acid biosynthetic enzymes were elevated during fruit maturation, leading to an increase in lipid production in the fruit mesocarp (Dussert et al., 2013; Bourgis et al., 2011; Tranbarger et al., 2011). In another study, variation in the expression level of several metabolic proteins, in addition to enzymes related to fatty acid biosynthesis, from various developing stages of the fruit was also observed (Loei et al., 2013). Nevertheless, the control of the biosynthetic processes that leads to higher oleic acid content in high oleic acid palms is still not understood although post-translational modification such as phosphorylation could play a role (Lau et al., 2016).

Fatty acid biosynthesis in plants occurs in both photosynthetic plastids such as leaf chloroplasts and in the non-photosynthetic plastids of flowers and fruit (Joyard et al., 2010; Benning, 2009; 2008; Stumpf, 1969). Chromoplasts are plastids found in ripened fruits (Bouvier et al., 1998). As the name suggests, chromoplasts contain pigments that confer the fruit colours (such as red, yellow and orange for oil palm mesocarp). While plastids normally develop directly from proplastids, chromoplasts are derived from chloroplasts (Ljubesic, 1972). Fatty acid synthesis in isolated intact chromoplasts has been reported (Kleiniq and Liedvogel, 1980). Proteomics analysis to characterise chromoplast proteins from various carotenoid-rich crops (Wang et al., 2013) had revealed more information on the metabolism and function of chromoplasts as well as their uniqueness in specific crop species.

An approach exploiting the fractionation power and sensitivity of liquid chromatography - tandem mass spectrometry (2DLC-MS/MS) was employed in conjunction with a mass spectrometer. The application of LC-MS / MS has become the technique of choice for most large-scale proteomic studies such as in yeast (Picotti et al., 2009), Arabidopsis (Wienkoop and Weckwerth, 2006) and Picea abies (Zulak et al., 2009). In related studies, Gueguen et al. utilised LC-MS/MS approach to understand the fatty acid and lipoic acid biosynthesis in plant mitochondria (Gueguen et al., 2000).
In this work, we describe the optimisation of offline 2DLC-MS/MS technique to capture the main enzymes associated with oleic acid biosynthesis from the oil palm mesocarp chromoplasts. Subsequently, the 2DLC-MS/MS approach in combination with iTRAQ labelling strategy were applied to examine the differential protein expressions in fruit mesocarps from low and high oleic acid palms at ripening stage $\left(20^{\text {th }}\right.$ week after anthesis). This work also provides reference datasets for any future experimental study of oil palm chromoplasts.

\section{MATERIALS AND METHODS}

\section{Plant Materials}

Fruit bunch from three progeny palms of Elaeis guineensis Jacq. var. tenera hybrid, generated from Deli dura x AVROS pisifera crosses was designated as the low oleic acid fruits. Fruit bunch from three progeny palms derived from the self-pollination of the Nigerian tenera palm (MPOB Breeding Population 12) was designated as the high oleic acid fruits due to their high iodine value (IV). The low oleic acid fruits contain about $37 \%$ oleic acid while the high oleic acid fruits have an average of $48 \%$ oleic acid (from the total fatty acid composition). These fruit bunches of $20^{\text {th }}$ week after anthesis were harvested from oil palm plantations located at MPOB-UKM Research Station at Bangi, Selangor and MPOB Hulu Paka Research Station at Terengganu, both in Malaysia. Fruitlets were randomly selected from each bunch. The mesocarps were cut into small pieces $(\sim 1 \mathrm{~cm})$, frozen under liquid nitrogen and then stored at $-80^{\circ} \mathrm{C}$ until proteomic analysis.

\section{Chromoplast Isolation and Subsequent Protein Extraction}

Extraction of proteins from the isolated oil palm chromoplasts were carried out according to Lau et al. (Lau et al., 2015). Lipids from the homogenised mesocarps were washed off sequentially with $10 \%$ trichloroacetic acid, 80\% methanol containing $0.1 \mathrm{M}$ ammonium acetate and $80 \%$ acetone. The pellet from the final wash was air-dried and resuspended in a mixture of cell wall digestive enzymes $\left(2 \% \mathrm{w} / \mathrm{v}\right.$ cellulase $\left[0.8 \mathrm{u} \mathrm{mg}^{-1}\right], 0.1 \% \mathrm{w} / \mathrm{v}$ pectinase [ $\left.1 \mathrm{U} \mathrm{mg}^{-1}\right], 0.6 \mathrm{M}$ sorbitol, 0.1 M DTT, 5 $\mathrm{mM}$ MES-KOH, $\mathrm{pH}$ 5.5). The suspension was then incubated in an incubator shaker (Labnet 211DS, Labnet Instrument, Inc., NJ, USA) for $6 \mathrm{hr}$ at $37^{\circ} \mathrm{C}$. After cell wall digestion, the mixture was sieved through two layers of Miracloth (Calbiochem, EMB Millipore Corporation, Billerica, MA) and the filtrate was centrifuged at $1750 \mathrm{~g}$ for $5 \mathrm{~min}$ at $4^{\circ} \mathrm{C}$ (RA-300 rotor, Kubota 7820, Kubota Corporation, 
Tokyo, Japan). The pellet was re-suspended in the extraction buffer $(0.7 \mathrm{M}$ sucrose, $1 \mathrm{M}$ Tris$\mathrm{HCl}, \mathrm{pH} 8.3,5 \mathrm{M} \mathrm{NaCl}, 50 \mathrm{mM}$ DTT, 1 mM EDTA) containing Roche protease inhibitors. The mixture was agitated for $5 \mathrm{~min}$ and then sonicated for 15 $\mathrm{min}$ at $4^{\circ} \mathrm{C}$. An equal volume of $50 \mathrm{mM}$, pH 8.0 Trissaturated phenol was added for phase separation. Proteins (in the upper phase) were precipitated gradually with five volumes of cold ammonium acetate-saturated methanol at $-20^{\circ} \mathrm{C}$ overnight. Protein pellets, acquired after centrifugation at $15000 \mathrm{~g}$ for $15 \mathrm{~min}$ at $4^{\circ} \mathrm{C}$ (RA-300 rotor, Kubota $7820)$, were washed with cold ammonium acetatesaturated methanol and $80 \%$ acetone prior to airdry. Commercial 2D Quant Kit (GE Healthcare Life Sciences, Uppsala, Sweden) was used to estimate the protein content. Bovine serum albumin was used as the calibration standard and each of the quantitation was performed in duplicates.

\section{Protein Digestion and Fractionation}

Digestions were executed according to Lau et al. (Lauet al.,2016). Fifty $\mu$ g of TCA/ acetone-precipitated proteins were re-suspended in $0.1 \mathrm{M}$ ammonium bicarbonate before reduction and alkylation using $50 \mathrm{mM}$ tris(2-carboxyethyl)phosphine and $150 \mathrm{mM}$ iodoacetamide, respectively. One percent sodium deoxycholate $(\mathrm{w} / \mathrm{v})$ was added before the protein digestion using a modified sequencing grade trypsin (Promega, Madison, WI, USA) for $16 \mathrm{hr}$ at $37^{\circ} \mathrm{C}$ (Koehn et al., 2011; Proc et al., 2010; Lin et al., 2008). Following the digestion, sodium deoxycholate was removed from the peptide extract by acidification with $0.5 \%$ formic acid and centrifugation at 14000 $\mathrm{g}$ for $15 \mathrm{~min}$ at ambient temperature. The peptide solution was dried in a centrifugal evaporator (CentriVap Concentrator). Strong cation exchange (SCX) fractionation - the peptide eluent was dried with a centrifugal evaporator (CentriVap Concentrator) and reconstituted in $50 \mu \mathrm{l}$ of $0.1 \% \mathrm{FA}$. The peptides were then fractionated using a $5 \mu \mathrm{m}$ SCX column packed with Spherisorb (BioX-SCX, $500 \mu \mathrm{m}$ ID, $15 \mathrm{~mm})$. Elution was done with 1\%, 5\%, $10 \%, 15 \%, 20 \%, 25 \%, 30 \%, 40 \%, 50 \%, 80 \%$ and $100 \%$ of $2 \mathrm{M}$ ammonium formate buffer $(\mathrm{v} / \mathrm{v})$ containing $2 \% \mathrm{ACN}, \mathrm{pH}$ 3.5. Each of the collected fractions was dried with a centrifugal evaporator (CentriVap Concentrator).

\section{Quantitation with Isobaric Tags}

Precipitated proteins from three different biological replicates of low and high oleic acid mesocarps, respectively, containing $200 \mu \mathrm{g}$ proteins each were resuspended in $300 \mu \mathrm{l} 0.5 \mathrm{M}$ triethylammonium bicarbonate, $\mathrm{pH} 8$ buffer prior to reduction and alkylation with $50 \mathrm{mM}$ tris(2carboxyethyl)phosphine and 150mMiodoacetamide, respectively. After $16 \mathrm{hr}$ of digestion with modified sequencing grade trypsin (Promega, Madison, WI, USA) in a 1:40 $\mu \mathrm{g}$ trypsin:protein ratio, the peptides solution was dried using a centrifugal evaporator (CentriVap Concentrator) and reconstituted in 50 $\mu \mathrm{l}$ of $0.5 \mathrm{M}$ triethylammonium bicarbonate, $\mathrm{pH} 8$. Labelling of the peptides with six different isobaric tags $(113,114,115,116,117$ and 118 iTRAQ reagents) was performed using commercial 8-plex iTRAQ reagents ( $\mathrm{AB}$ Sciex Pte. Ltd., CA, USA). The dried labelled peptide pellet was reconstituted in $200 \mu 1$ of $0.1 \%$ formic acid. Acetonitrile, methanol and $0.1 \%$ formic acid-conditioned Empore solid phase extraction disk (3M Company, MN, CA) was added to the peptides solution. Incubation at ambient temperature with gentle agitation for $4 \mathrm{hr}$ enables the binding of peptides to the C18 membrane disk. Elution of the bound peptides was done sequentially with $50 \%$ and $75 \%$ ACN in $0.1 \%$ FA for $2.5 \mathrm{hr}$. The eluent was dried in a centrifugal evaporator (CentriVap Concentrator) and reconstituted in $30 \mu 1$ of $0.1 \%$ FA. The labelled peptides were fractionated using a SCX column (Phenomenex SCX cartridge, 4 x $2 \mathrm{~mm}$ ). Elution was done with 3\%, 6\%, 10\%, 15\%, $20 \%, 25 \%, 40 \%, 80 \%$ and $100 \%$ of $2 \mathrm{M}$ ammonium formate buffer $(\mathrm{v} / \mathrm{v})$ containing $2 \% \mathrm{ACN}, \mathrm{pH} 3.5$. Each of the collected fractions was then dried with centrifugal evaporator (CentriVap Concentrator).

\section{Liquid Chromatography-tandem Mass Spectro- metry Analysis}

LC-MS / MS analysis were conducted according to Lau et al. (Lau et al., 2016), except for the iTRAQ quantitation. Peptides were separated using a nano-Advance Splitless nanoLC system (Bruker Daltonik, Bremen, Germany) connected to the amaZon speed ETD ion trap mass spectrometer (Bruker Daltonik). Five $\mu 1$ of reconstituted tryptic digests in $0.1 \%$ formic acid (FA) and $5 \% \mathrm{ACN}$ was injected into the nanoLC system for separation using an Intensity $\mathrm{C} 18 \mathrm{P}(1.8 \mu, 0.1 \times 300 \mathrm{~mm})$ (Bruker-Michrom Bioresources, Inc., Auburn, CA, USA) reverse-phase column equilibrated with $95 \%$ solvent A ( $2 \% \mathrm{ACN}, 0.1 \% \mathrm{FA})$ and $5 \%$ solvent $\mathrm{B}$ (98\% ACN, 0.1\% FA). Gradient of 0\%-45\% solvent $\mathrm{B}$ in $45 \mathrm{~min}$ was used to elute the bound peptides at a flow rate of $400 \mathrm{nl} \mathrm{min}{ }^{-1}$. The eluted peptides were electrosprayed into the ion trap mass spectrometer with a spray voltage of $1300 \mathrm{~V}$ and a capillary temperature of $150^{\circ} \mathrm{C}$. Precursor survey scan was acquired with mass ranged from $\mathrm{m} / \mathrm{z}$ 310-1400. The resolution was fixed at 'Enhanced Resolution' and the scanning speed was $8100 \mathrm{u} \mathrm{s}^{-1}$. Tandem MS condition consisted of 'Xtreme Resolution' scan ranged from $\mathrm{m} / \mathrm{z}$ 100-3000. Three of the most intense multiple charged peptide ions $(1+, 2+$, and $3+)$ in every scan were fragmented via collisioninduced dissociation. Tandem mass spectra were 
collected using $1.00 \mathrm{~V}$ of fragmentation amplitude, an isolation window of $4.0 \mathrm{u}$ and scanning speed of $52000 \mathrm{u} \mathrm{s}^{-1}$. iTRAQ quantitation - iTRAQ labelled SCX-fractionated peptides were eluted using a gradient of $2 \%-65 \%$ solvent B in $60 \mathrm{~min}$ at a flow rate

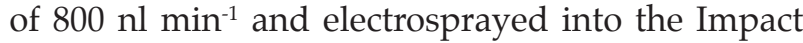
HD quadrupole time-of-flight mass spectrometer (Bruker Daltonik) with a spray voltage of $1300 \mathrm{~V}$ and a capillary temperature of $150^{\circ} \mathrm{C}$. Precursor survey scan was acquired with a mass range from $\mathrm{m} / \mathrm{z} 350$ 1200. MS/MS scan ranged from $\mathrm{m} / \mathrm{z}$ 50-2200. Up to 10 of the most intense multiple charged peptide ions $(1+, 2+$, and $3+)$ per scan were fragmented via collision-induced dissociation.

\section{Data Acquisition and Analysis}

Identification of the proteins was accomplished according to Lau et al. (Lau et al., 2016), except to analyse the quantitation data. Mass spectra datasets were acquired with ESI Compass 1.4 for amaZon (trapControl Version 7.1) (Bruker Daltonik) in positive mode. Data deconvolutions and subsequent analysis were performed using Compass DataAnalysis (Version 4.1 SR1) (Bruker Daltonik). DataAnalysis Script Editor was employed to interpret the mass spectra data. These peak lists in an eXtensible Markup Language (XML) format were sent to ProteinScape data management (Version 3.1) (Bruker Daltonik) for protein identification. The protein identifications were executed with tandem mass spectrometry peak lists using Mascot database search (Matrix Science, London, United Kingdom). The peptide sequences were searched against selected Arabidopsis thaliana, Elaeis species, Zea mays, Brassica oryza plant taxonomies (308 973 sequences as on 24 December 2013) in Uniprot protein database (to reduce search time) and protein compilation was done using the Protein Extractor module in ProteinScape.

Peptide and fragment ion mass tolerances were fixed at $100 \mathrm{ppm}$ and $0.6 \mathrm{Da}$, respectively; and the instrument was specified as an 'ESI trap'. Protease used was 'semi-trypsin' with two missing cleavages. Carbamidomethylation was the fixed modification on cysteine while oxidation of methionine and deamidation of asparagine and glutamine were set as other variable modifications. Proteins were accepted if they had at least one 'Rank 1' peptide with an peptide ion score of more than $50.0(\mathrm{P}<0.05)$. All database searches were also performed on the 'decoy' database to cap the false discovery rate at $2 \%$. The decoy database consisted of randomised sequences of the searched taxonomies. Individual identified protein list (for fractions) were compiled using the Protein Extractor module in ProteinScape. The iTRAQ quantitation - data acquisitions were performed using Compass for otofSeries 1.5 (for otofControl Version 3.2) (Bruker Daltonik).

The Impact HD quadrupole time-of-flight was internally calibrated using Electrospray Tuning Mix Positive (Agilent Technologies, Inc., Santa Clara, CA, USA). Data analysis were performed using the Compass DataAnalysis (Version 4.1 SR1) (Bruker Daltonik). For protein identification, peptide sequences were searched against the same taxonomies described above. Peptide and fragment ion mass tolerances were set to $20 \mathrm{ppm}$ and $0.1 \mathrm{Da}$, respectively; and the instrument was specified as an 'ESI-QUAD-TOF'. Semi-trypsin was designated as the protease with two missed cleavages. Carbamidomethylation on cysteine and iTRAQ8plex (on lysine and $\mathrm{N}$-terminal) were set as the fixed modifications while oxidation of methionine, deamidation (of asparagine and glutamine) and iTRAQ8plex of tyrosine were set as variable modifications. Proteins were accepted if they had at least one top ranking peptide (Rank 1) with a Mascot ion score of more than 50.0, indicating identity or extensive homology $(\mathrm{P}<$ 0.05). All database searches were also performed on the 'decoy' database to cap the false discovery rate at $2 \%$. Individual identified protein list of each strong cation exchange fractions and two iTRAQ experiments were compiled using the Protein Extractor module in ProteinScape.

For relative protein quantitation analysis of identified iTRAQ labelled peptides with inhouse Mascot server, the XML format peak lists of all the strong cation exchange fractions were compiled into a single Mascot Generic Format file using the 'Export MGF' functionality in ProteinScape. Statistical test for the quantitation analysis was performed using Mascot algorithm based on the Reporter Protocol (Matrix Science, London, United Kingdom). The method to calculate a protein ratio from a set of peptide ratio is weighted. In this method, summation of the intensity values for the tested set of peptides are used in the calculation of the summed values. Summed intensities in the Reporter Protocol was used for normalisation. The iTRAQ quantitation method contained the mass of the reporter ions used, their ratios and the specific modifications for iTRAQ (as described above). At least two peptides were used for the quantitation of their abundance.

\section{RESULT}

Offline 2DLC-MS/MS Optimisation to Improve the Detection of Fatty Acid Biosynthetic Enzymes

A gel-free approach (2DLC-MS/MS) was applied to investigate the expression of fatty acid biosynthetic enzymes. Essentially, chromoplast 
peptides from low and high oleic acid mesocarps were fractionated using a SCX column before their subsequent separation with a reverse phase column for mass spectrometric characterisation. Different fractionation ranges were attempted to capture all the fatty acid biosynthetic enzymes. Figure 1 shows an important trend on the effect of different fractionation ranges on the number of identified peptides and proteins. The number of peptides increased from 114 peptides to 417 peptides identified using the third fractionation range. In addition, three times as many of the identified proteins using the third fractionation range had Mascot scores $>60$.

Table 1 summarises the number of peptides related to fatty acid biosynthesis eluted with the tested fractionation ranges using different percentages of ammonium formate. The majority of fatty acid biosynthetic peptides eluted in the $1 \%$ to $25 \%$ range. The peptides eluting later $(30 \%$ $80 \%$ ) were mostly the same peptides or redundant peptides that had eluted by $25 \%$. Furthermore, the previously undetected $\beta$-ketoacyl-ACP synthase peptides (using the first and second fractionation ranges) successfully eluted within the third fractionation range. Peptides for stearoyl-ACP desaturase also eluted earlier in the $1 \%$ and 5\% fractions (with the third fractionation range). The successful detection of these two enzymes is highly significant in terms of being able to evaluate potential expression differences between low and high oleic acid mesocarps. Table 1 also indicates that more peptides were eluted per fraction using the third fractionation range while the first fractionation range generated the least number of peptides per fraction. With the exception of acetylCoA carboxylase and stearoyl-ACP desaturase, peptides from all proteins related to fatty acid biosynthesis were also present in the flow through eluate, indicating that they were present in higherabundance relative to acetyl-CoA carboxylase and stearoyl-ACP desaturase.

Figure 2 presents the number of nonredundant unique peptides and sequence coverage corresponding to the fatty acid biosynthetic enzymes, compiled from three biological replicates of each mesocarp. The stearoyl-ACP desaturase from the low oleic acid mesocarp had a higher number of peptides (7, compared to high oleic mesocarp with 4 peptides), covering $23 \%-25 \%$ of the stearoyl-ACP desaturase full sequence. The offline 2DLC-MS/MS approach also identified more peptides that were matched to $\beta$-ketoacylACP synthase and stearoyl-ACP desaturase than GeLC-MS/MS (data not shown). In contrast, fewer peptides were detected for both $\beta$-hydroxyacylACP dehydrogenase and 3-enoyl-ACP desaturase and they had lower sequence coverage.

\section{Isobaric Tags Reveal the Differential Expression of Fatty Acid Biosynthetic Enzymes}

Changes in the protein expressions of fatty acid biosynthetic enzymes between low and high oleic acid palms were quantitated using an isobaric tag labelling strategy. Three biological replicates from low and high oleic acid mesocarps were individually labelled with iTRAQ reagents and separated using the optimised offline 2DLC-MS / MS. To examine the dynamics of the proteome changes between low and high oleic acid palms, the normalised protein ratios from all three replicates of low oleic acid mesocarp were compared to those from the three replicates of high oleic acid mesocarp (from two different iTRAQ experiments) (Data in S1). In-house Mascot server results indicated that $\beta$-hydroxyacyl-ACP dehydrogenase and $\beta$-ketoacyl-ACP synthase were up-regulated (ratios of 0.905 and 0.902 , respectively)

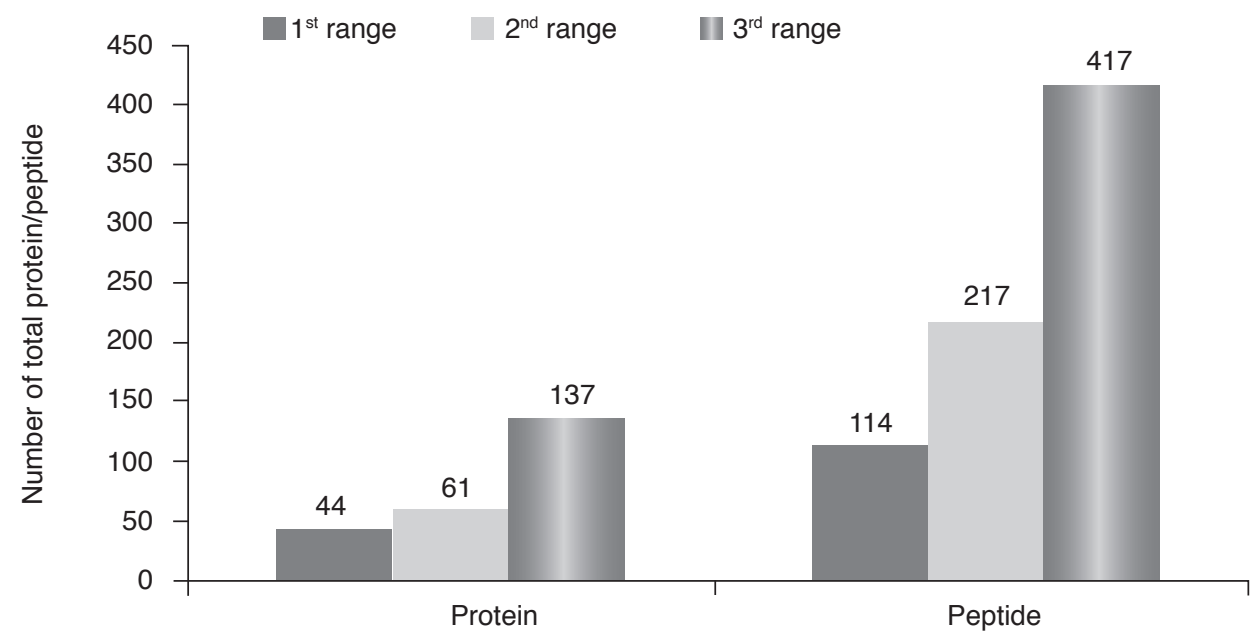

Figure 1. Total number of proteins and peptides observed with a Mascot score of more than 60 and 35, respectively. These data were generated from the compiled proteins of low oleic acid and high oleic acid biological replicates obtained with offline 2DLC-MS/MS. 
TABLE 1. DISTRIBUTION OF PEPTIDES PER FATTY ACID BIOSYNTHETIC ENZYMES OVER THE COLLECTED STRONG CATION EXCHANGE FRACTIONS COMPILED FROM THREE BIOLOGICAL REPLICATES FOR LOW AND HIGH OLEIC ACID MESOCARPS

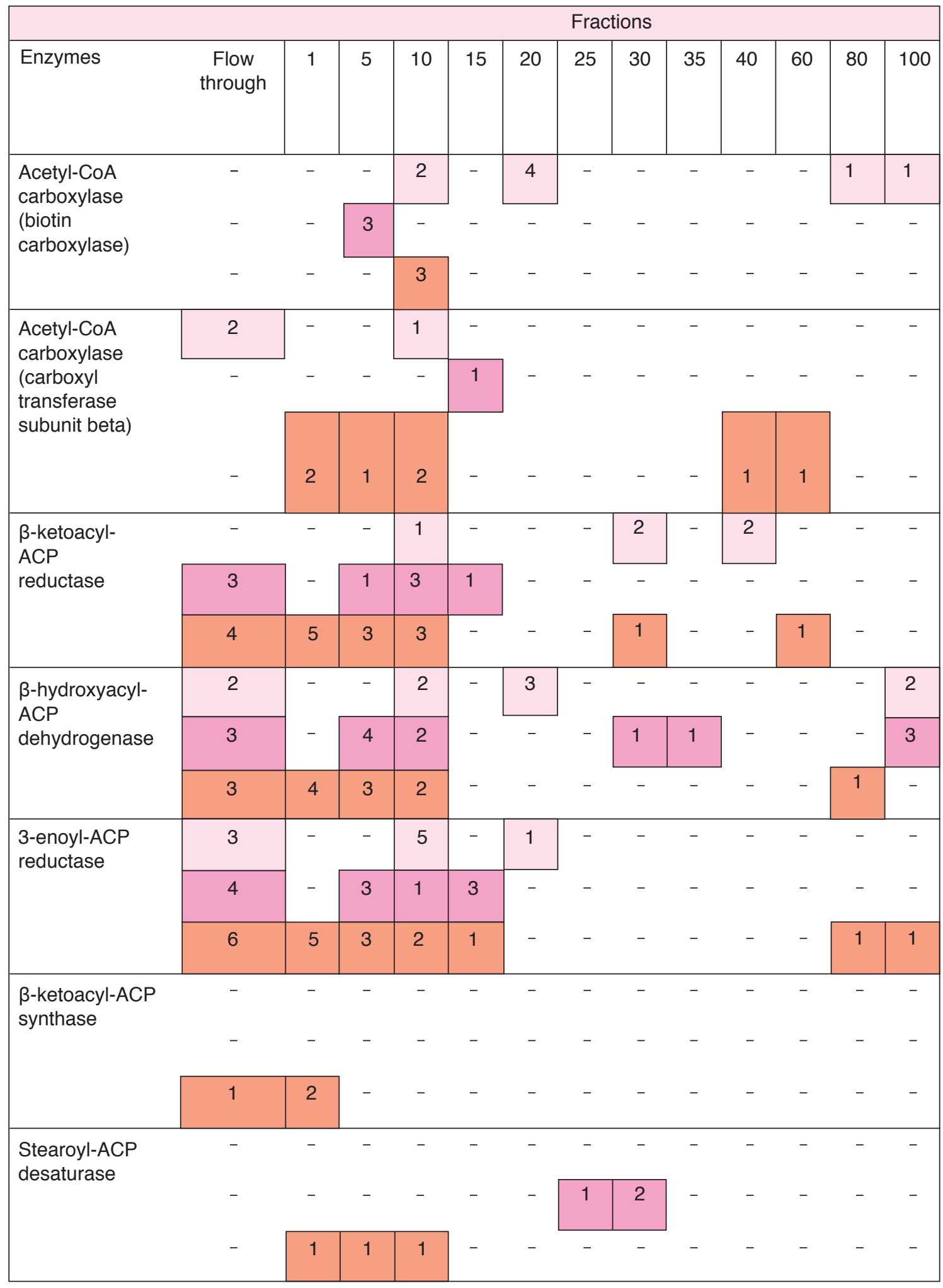

Note: Coloured boxes indicate the different fractionation ranges. The numbers in the boxes indicate the number of peptides that matched to the respective fatty acid biosynthetic enzyme. The percentages indicate the concentration of ammonium formate used $(\mathrm{v} / \mathrm{v})$. 

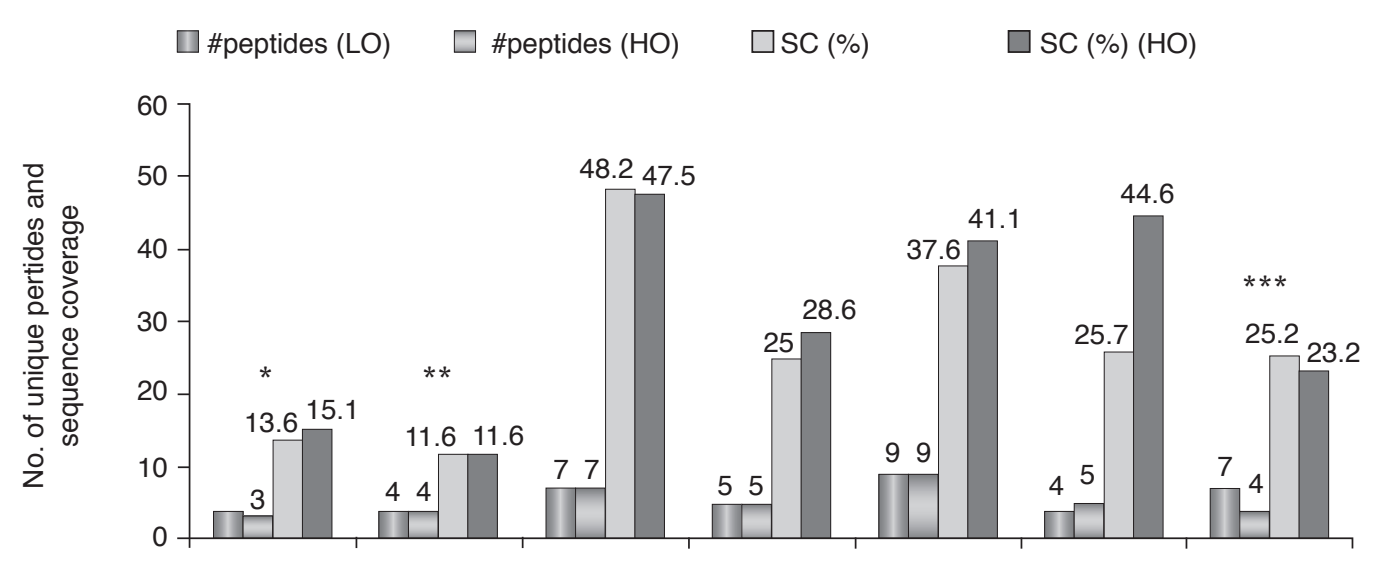

Note: * And ${ }^{* *}$ denote the subunits of acetyl-CoA carboxylase. ${ }^{* * *}$ Indicates the key enzyme in oleic acid biosynthesis.

Figure 2. Number of unique peptides and sequence coverage (SC) per fatty acid biosynthetic enzyme obtained with an offline 2DLC-MS/MS.

The results were compiled from three biological replicates for each low oleic acid (LO) and high oleic acid $(H O)$ varieties.

$(\mathrm{P}<0.05)$ in the high oleic acid mesocarp. The 3-enoyl-ACP reductase exhibited a decrease (ratio of 1.088) $(\mathrm{P}<0.05)$ in expression level in the high oleic acid mesocarp while acetyl-CoA carboxylase was considered not to show any alteration in the expression level (ratio of 0.959). The same unique peptide from both mesocarps is needed to make a relative estimation of protein abundance. Since this was not achievable for $\beta$-ketoacyl-ACP reductase and stearoyl-ACP desaturase, differences in their expressions could not be determined.

Two separate iTRAQ experiments identified a total of 114 proteins and 140 proteins, respectively, with at least 95\% confidence using the in-house Mascot server. Other metabolic enzymes; fructosebiphosphate aldolase (ration of 0.92) and malate dehydrogenase (ratio of 0.94) were up-regulated $(\mathrm{P}<0.05)$ in the high oleic acid mesocarp while sucrose synthase was down-regulated (ratio of 1.16). The expression level of several proteins involved in ATP and NADPH binding was also increased as the oil palm fruit produced more oleic acid. Notably, lipase, which is involved in lipid metabolism, was expressed less (ratio of 1.34) in high oleic acid mesocarp.

\section{DISCUSSION}

\section{Offline 2DLC-MS/MS and Subsequent Quantitation of Fatty Acid Biosynthetic Enzymes' Expression}

In higher plants, plastidial acetyl-coenzyme A (CoA) is used to generate malonyl-CoA for fatty acid biosynthesis. This reaction is catalysed by acetyl-CoA carboxylase (ACCase). In these studies, an offline 2DLC-MS/MS approach successfully detected and separated both the main subunits of multisubunit heteromeric complex of ACCase. Mass spectrometric analysis of iTRAQ labelled ACCase peptides showed no significant changes in its expression between low and high oleic acid mesocarps. However, Roesler et al. demonstrated that transgenic plants with 10- to 20-fold increase in the enzymatic activity of ACCase resulted in the enrichment of oleic acid in the Brasscia napus seeds (13.7\% increment in oleic acid content) (Roesler et al., 1997). Increment in the expression of ACCase from $12^{\text {th }}$ week after anthesis until fruit maturation was also observed by Loei et al., although the expression was compared between low-oil-yielding fruits and high-oil-yielding fruits (Loei et al., 2013). Since the high oleic mesocarp has $10.2 \%$ more oleic acid than the low oleic acid mesocarp, the expression of ACCase was expected to show up-regulation but that was not the case in oil palm mesocarp. These results could possibly be explained by studies that reported the effect of enhanced ACCase activity varied in different plant organelles (seed and leaf) (Madoka et al., 2002). Another explanation may be that the heteromeric form of ACCase is too labile to be isolated (Sasaki and Nagano, 2004). Therefore, the number of peptides detected for both subunits of ACCase might not reflect the actual number of peptides in mesocarp. Previous studies of fatty acid biosynthesis in plants also implicated the importance of ACCase for regulation. However, these studies were focused on the overall production of lipids and not specifically on oleic acid (Chen et al., 2009; Klaus et al., 2004; Thelen and Ohlrogge, 2002b; Page et al., 1994; Post-Beittenmiller et al., 1992).

The elongation of the carbon units to 16- or 18-carbon (C16:0, C18:0) fatty acid is carried out by Type II fatty acid synthase (FAS) (Type I FAS present in animals and fungi) (Joyard et al., 2010). This easily dissociable multisubunit complex consists of $\beta$-ketoacyl-ACP reductase, $\beta$-hydroxyacyl- 
ACP dehydrogenase, 3-enoyl-ACP reductase and $\beta$-ketoacyl-ACP synthase (KAS). Based on the offline 2DLC-MS/MS results, these enzymes (except for $\beta$-ketoacyl-ACP synthase), were found to have more detected peptides in both mesocarps compared to acetyl-CoA carboxylase, $\beta$-ketoacyl-ACP synthase and stearoyl-ACP desaturase. Subsequent quantitation results indicated that $\beta$-hydroxyacylACP dehydrogenase was expressed slightly more while 3-enoyl-ACP reductase displayed slightly lower expression level in high oleic acid mesocarp (but significantly, $\mathrm{p}<0.05$ ). The $\beta$-hydroxyacyl-ACP dehydrogenase produces 16-carbon palmitoyl-ACP (C16:0-ACP), which is the final product of fatty acid elongation. The relatively higher expression of $\beta$-hydroxyacyl-ACP dehydrogenase in high oleic acid mesocarp could functionally increase the production of palmitoyl-ACP, which is the precursor for 18-carbon stearoyl-ACP. The 3-enoyl$\mathrm{ACP}$ reductase regenerates acyl-ACP for the next cycle of fatty acid biosynthesis. Unexpectedly, the expression of 3-enoyl-ACP reductase was lower in the high oleic acid mesocarp. However, FAS genes were reported to be down-regulated during the peak of lipid accumulation at $20^{\text {th }}$ WAA in E. guineensis (Singh et al., 2013b). In addition, a number of the core genes of fatty acid biosynthesis that were genetically overexpressed or under expressed in transgenic soyabean or Brassica napus seeds did not show any significant increase or only a marginal increase in seed oil yield (Ohlrogge and Jaworski, 1997; Roesler et al., 1997). In a different study, the overexpression of spinach KAS III in tobacco had even decreased the fatty acid content (Dehesh et al., 2001). The expression levels of $\beta$-hydroxyacylACP dehydrogenase was also reported to increase throughout the developing stages in low-oilyielding and high-oil-yielding fruits (Loei et al., 2013). The expression level of $\beta$-ketoacyl-ACP reductase decreased in high-oil-yielding fruits while the expression level of 3-enoyl-ACP reductase did not change much.

The findings from the quantitation analysis revealed a slight increase in the expression of KAS. KAS has three isoforms, which were not able to be distinguished in this study. KAS III essentially initiates the condensation reaction between acetyl-CoA and malonyl-ACP and the subsequent condensations between these two building blocks are performed by KAS I. KAS II is implicated in the final addition of 2-carbon to 16-carbon palmitoylACP to produce the 18-carbon stearoyl-ACP (C18:0$\mathrm{ACP})$. Therefore, it was anticipated that expression of KAS II would be up-regulated to supply the stearoyl-ACP in high oleic acid mesocarp, at the expense of palmitoyl-ACP. Since the results indicated that the expression of KAS was slightly elevated (but significantly, $\mathrm{p}<0.05$ ) in high oleic acid mesocarp, the identified KAS in this study could well be KAS II. Increasing the expression of KAS II had raised the production of C18:1-ACP, as demonstrated in previous study (Guerin et al., 2016; Sambanthamurthi et al., 1999). Loei et al. also described an increased in the expression of KAS in mature high-oil-yielding fruits but as observed in this study, their isoforms were not able to be differentiated (Loei et al., 2013).

Stearoyl-ACP desaturase (SAD) is the key fatty acid biosynthetic enzyme that introduces the double bond into the saturated stearoyl-ACP (C18:0-ACP) to produce mono-unsaturated oleoyl-ACP (C18:1$A C P)$. As SAD was not detected in the quantitative evaluation, the relative abundance of this enzyme between the two mesocarps could not be determined. However, results from the offline 2DLC-MS/MS showed no substantial difference in the detected number of peptides between low and high oleic acid mesocarps. This observation contrasted with the findings from previous studies as the expression of SAD was up-regulated in oleic acid accumulating tissues in earlier published work. Loei et al. described that the level of SAD in oil-accumulating fruit had been elevated although the result could not be validated either (Loei et al., 2013). Kilaru et al. also reported that the up-regulation of SAD in avocado was likely to be involved in increasing the high oleic acid level in mesocarp oil (Kilaru et al., 2015). Plants defective in SAD were also reported to accumulate high levels of C18:0-ACP and low level of C18:1-ACP fatty acids (Kachroo et al., 2007; 2003). A potential explanation of the non-existent upregulation of SAD in high oleic acid mesocarp is the feedback inhibition mechanism by the end product; oleic acid. The accumulation of oleic acid could result in the inhibition or even down-regulation of SAD, which control its synthesis. Purified monomeric ACCases from maize, diatom and Brassica napus were revealed to be inhibited by palmitoyl-CoA (Roessler, 1990; Nikolau and Hawke, 1984) and stearoyl-ACP (Andre et al., 2012). Decanoyl-ACP was also reported to inhibit KAS activity in canola, spinach and Cuphea (Schuch et al., 1997; Bruck et al., 1996). The exact mechanism regulating this feedback in fatty acid biosynthesis is unknown (Ramli et al., 2002a; Shintani and Ohlrogge, 1995). This feedback could occur through biochemical or post-translational modified fatty acid biosynthetic enzymes (Andre et al., 2012). The relevance of feedback inhibition in this study is unclear because the changes in the pools of stearoyl-ACP and oleoyl$\mathrm{ACP}$ were not measured.

The findings of this study also underline the prospect of other metabolic enzymes in regulating oleic acid level in the high oleic mesocarp. Several enzymes involved indirectly with fatty acid biosynthesis have been observed to be regulated differently between low and high oleic acid mesocarps. Notably, the increased levels of fructose- 
biphosphate aldolase and malate dehydrogenase could shift the carbon flux towards fatty acid biosynthesis. Fructose-biphosphate aldolase generates triose phosphates, dihydroxyacetone phosphate and glyceraldehyde 3-phosphate to produce pyruvate via the glycolysis pathway. Meanwhile, malate dehydrogenase is involved in the production of glucose via gluconeogenesis through the oxidation of malate to oxaloacetate. The synthesis of glucose may also be enhanced in the high oleic acid mesocarp through the reduction in the expression of sucrose synthase, which produces sucrose at the expense of glucose. Hence, the increased supplies of glucose and pyruvate in the high oleic acid mesocarp may elevate the supply of acetyl-CoA, the essential fatty acid biosynthesis precursor. A decrease in the expression of lipase, which catalyses the metabolism of oleic acid esters, could also give rise to the level of oleic acid in the high oleic acid mesocarp, albeit indirectly. The results agreed with a study on sunflower seeds that reported the lowered oil content as the effect of lowered activities of glycolytic enzymes. Likewise, the level of seed oil in Arabidopsis was found to be affected by pyruvate kinase (Troncoso-Ponce et al., 2010; Andre et al., 2007).

The expression levels of elongation factor 1-alpha and ribulose 1,5-biphosphate carboxylase/ oxygenase large subunit were also found to be differentially regulated. Fatty acid biosynthesis is an anabolic process that demands an abundant supply of ATP and NADPH. Therefore, the reduced expression of these photosynthetic proteins in high oleic acid might drive metabolic resources such as ATP and NADPH toward metabolic processes related to lipid biosynthesis, for example, glycolysis and fatty acid biosynthesis. In addition to the reduction of other metabolic processes that utilise ATP, the decrease in the expression of nucleoside diphosphate kinase 1 and elevated expressions of two uncharacterised proteins involved in ATP binding may enhance the supply of ATP for lipid biosynthesis. Loei et al. had found a reduction in the level of expressions of proteins that compete for metabolic resources such as ATP and NADPH with the whole lipid biosynthesis process (Loei et al., 2013).

This study describes the isolation and identification of six main fatty acid biosynthetic enzymes from oil palm fruit mesocarp through the application of an offline 2DLC-MS/MS technique. Comparative analysis between low and high oleic acid oil palm mesocarps revealed that three of these fatty acid biosynthetic enzymes (based on the iTRAQ experiments), were differentially regulated. The findings also indicated that other metabolic proteins associated with fatty acid production could be correlated with the different content of oleic acid in the oil palm mesocarp. Findings from this study provide a clearer understanding on the fatty acid biosynthesis regulation in oil palm. Further validation of the enzymes showing differential regulations using a time course-based studies is required to corroborate their biological significance on oleic acid production in oil palm fruit.

\section{SUPPORTING INFORMATION}

S1 Data. iTRAQ quantitation analysis.

\section{ACKNOWLEDGEMENT}

The author would like to thank the Director-General of MPOB for permission to publish this article. The author also thanks MPOB for the funding of the project and the Breeding and Quantitative Genetics Group for the provision of oil palm fruit bunches. The author also wishes to acknowledge AgResearch Lincoln Research Centre for the use of the research facilities. The authors declare that they have no competing interests.

\section{REFERENCES}

ANDRE, C; FROEHLICH, J E; MOLL, M R and BENNING, C (2007). A heteromeric plastidic pyruvate kinase complex involved in seed oil biosynthesis in Arabidopsis. Plant Cell, 19: 2006-2022.

ANDRE, C; HASLAM, R P and SHANKLIN, J (2012). Feedback regulation of plastidic acetyl-CoA carboxylase by 18:1-acyl carrier protein in Brassica napus. Proc. Natl. Acad.Sci. USA, 109: 10107-10112.

BENNING, C (2008). A role for lipid trafficking in chloroplast biogenesis. Progress in Lipid Research, 47: 381-389.

BENNING, C (2009). Mechanisms of lipid transport involved in organelle biogenesis in plant cells. Annu Rev Cell Dev Biol, 25: 71-91.

BOURGIS, F; KILARU, A; CAO, X; NGANDOEBONGUE, G F; DRIRA, N; OHLROGGE, J B and ARONDEL, V (2011). Comparative transcriptome and metabolite analysis of oil palm and date palm mesocarp that differ dramatically in carbon partitioning. Proc. Natl. Acad . Sci., USA, 108: 1252712532.

BOUVIER, F; BACKHAUS, R A and CAMARA, $B$ (1998). Induction and control of chromoplastspecific carotenoid genes by oxidative stress. J. Biological Chemistry, 273: 30651-30659. 
BRUCK, F; BRUMMEL, M; SCHUCH, R and SPENER, F (1996). In-vitro evidence for feedback regulation of $\beta$-ketoacyl-acyl carrier protein synthase III in medium-chain fatty acid biosynthesis. PLANTA, 198: 271-278.

CHEN, M; MOONEY, B P; HAJDUCH, M; JOSHI, T; ZHOU, M; XU, D and THELEN, J J (2009). System analysis of an Arabidopsis mutant altered in de novo fatty acid synthesis reveals diverse changes in seed composition and metabolism. Plant Physiol, 150: 2741.

DAUQAN, E M A; ABDULLAH SANI, H; ABDULLAH, A and MOHD KASIM, Z (2011). Fatty acids composition of four different vegetable oils (red palm olein, palm olein, corn oil and coconul oil) by gas chromatography. $2^{\text {nd }}$ International Conference on Chemistry and Chemical Engineering (IPCBEE). IACSIT Press. p. 31-34.

DEHESH, K; TAI, H; EDWARDS, P; BYRNE, J and JAWORSKI, J G (2001). Overexpression of 3-ketoacylacyl-carrier protein synthase IIIs in plants reduces the rate of lipid synthesis. Plant Physiol, 125: 11031114 .

DUSSERT, S; GUERIN, C; ANDERSSON, M; JOËT, T; TRANBARGER, T J; PIZOT, M; SARAH, G; OMORE, A; DURAND-GASSELIN, T and MORCILLO, F (2013). Comparative transcriptome analysis of three oil palm fruit and seed tissues that differ in oil content and fatty acid composition. Plant Physiology, 162: 1337-1358.

GUEGUEN, V; MACHEREL, D; JAQUINOD, M; DOUCE, R and BOURGUIGNON, J (2000). Fatty acid and lipoic acid biosynthesis in higher plant mitochondria. J. of Biological Chemistry, 275: 5016-25.

GUERIN, C; JOET, T; SERRET, J; LASHERMES, P; VAISSAYRE, V; AGBESSI, M D; BEULE, T; SEVERAC, D; AMBLARD, P; TREGEAR, J; DURAND-GASSELIN, T; MORCILLO, F and DUSSERT, S (2016). Gene coexpression network analysis of oil biosynthesis in an interspecific backcross of oil palm. Plant Journal. In press.

JOYARD, J; FERRO, M; MASSELON, C; SEIGNEURIN-BERNY, D; SALVI, D; GARIN, J and ROLLAND, N (2010). Chloroplast proteomics highlights the subcellular compartmentation of lipid metabolism. Progress in Lipid Research, 49: 128-158.

KACHROO, A; LAPCHYK, L; FUKUSHIGE, H; HILDEBRAND, D; KLESSIG, D and KACHROO, P (2003). Plastidial fatty acid signaling modulates salicylic acid- and jasmonic acid-mediated defense pathways in the Arabidopsis ssi2 mutant. Plant Cell, 15: 2952-2965.
KACHROO, A; SHANKLIN, J; WHITTLE, E; LAPCHYK, L; HILDEBRAND, D and KACHROO, P (2007). The Arabidopsis stearoyl-acyl carrier protein-desaturase family and the contribution of leaf isoforms to oleic acid synthesis. Plant Mol Biol, 63: 257-271.

KILARU, A; CAO, X; DABBS, P B; SUNG, H J; RAHMAN, M M; THROWER, N; ZYNDA, G; PODICHETI, R; IBARRA-LACLETTE, E; HERRERAESTRELLA, L; MOCKAITIS, $\mathrm{K}$ and OHLROGGE, J B (2015). Oil biosynthesis in a basal angiosperm: transcriptome analysis of Persea Americana mesocarp. BMC Plant Biology, 15: 203.

KIRKLAND, R (2011). The Role of Palm Oil in a Sustainable Dairy Industry [Online]. United Kingdom: Volac Internation Limited. http: / / www.volac.com/ news / agriculture-news / news236/ palm-oil-in-asustainable-world, accessed on 4 June 2013.

KLAUS, D; OHLROGGE, J B; NEUHAUS, H E and DORMANN, P (2004). Increased fatty acid production in potato by engineering of acetyl-CoA carboxylase. PLANTA, 219: 389-396.

KLEINIQ, H and LIEDVOGEL, B (1980). Fatty acid synthesis by isolated chromoplasts from the daffodil. Energy sources and distribution patterns of the acids. Planta, 150: 166-169.

KOEHN, H; LAU, B; CLERENS, S; PLOWMAN, J E; DYER, J M; RAMLI, U S and DEB-CHOUDHURY, $S$ (2011). Combination of acid labile detergent and C18 Empore disks for improved identification and sequence coverage of in-gel digested proteins. Analytical and Bioanalytical Chemistry, 400: 415-421.

LAU, B Y; CLERENS, S; MORTON, J D; DYER, J M; DEB-CHOUDHURY, S and RAMLI, U S (2016). Application of a mass spectrometric approach to detect the presence of fatty acid biosynthetic phosphopeptides. Protein J., 35: 163-170.

LAU, B Y; DEB-CHOUDHURY, S; MORTON, J D; CLERENS, S; DYER, J M and RAMLI, U S (2015). Method developments to extract proteins from oil palm chromoplast for proteomic analysis. Springerplus, 4: 791.

LIN, Y; ZHOU, J; BI, D; CHEN, P; WANG, X and LIANG, S (2008). Sodium-deoxycholate-assisted tryptic digestion and identification of proteolytically resistant proteins. Analytical Biochemistry, 377: 259266.

LJUBESIC, N (1972). Ultrastructural changes of plastids during the yellowing of the fruit of Cucurbita pepo var pyriformis. Acta Botanical Croatica, 31: 47-53. 
LOEI, H; LIM, J; TAN, M; LIM, T K; LIN, Q S; CHEW, F T; KULAVEERASINGAM, $\mathrm{H}$ and CHUNG, M C (2013). Proteomic analysis of the oil palm fruit mesocarp reveals elevated oxidative phosphorylation activity is critical for increased storage oil production. J Proteome Res, 12: 5096-5109.

MADOKA, Y; TOMIZAWA, K; MIZOI, J; NISHIDA, I; NAGANO, Y and SASAKI, Y (2002). Chloroplast transformation with modified accD operon increases acetyl-CoA carboxylase and causes extension of leaf longevity and increase in seed yield in tobacco. Plant Cell Physiol, 43: 1518-1525.

MAEDER, M L and GERSBACH, C A (2016). Genome-editing technologies for gene and cell therapy. Molecular Therapy, 24: 430-446.

MCFERRON, W (2013). Record global palm oil output seen raising vegetable oil supply. Bloomberg Business, 16 July 2013.

NIKOLAU, B J and HAWKE, J C (1984). Purification and characterization of maize leaf acetyl-coenzyme A carboxylase. Archives of Biochemistry and Biophysics, 228: 86-96.

OHLROGGE, J B and JAWORSKI, J G (1997). Regulation of fatty acid synthesis. Annu Rev Plant Physiol Plant Mol Biol, 48: 109-136.

PAGE, R A; OKADA, S and HARWOOD, J L (1994). Acetyl-CoA carboxylase exerts strong flux control over lipid synthesis in plants. Biochim Biophys Acta, 1210: 369-372.

PARVEEZ, G; RASID, O; MASANI, $M$ and SAMBANTHAMURTHI, R (2015). Biotechnology of oil palm: strategies towards manipulation of lipid content and composition. Plant Cell Reports, 34: 533543.

PARVEEZ, G K; OTHMAN, A; RAMLI, U S; SAMBANTHAMURTHI, R; YUNUS, A M M; HASHIM, A T; DIN, A $\mathrm{K}$ and WAHID, M B (2010). Improving value of oil palm using genetic engineering. Biocatalysis and Molecular Engineering (Hou, C T and Shaw, J F eds.). John Wiley \& Sons, Inc. p. 67-81.

PICOTTI, P; BODENMILLER, B; MUELLER, L N; DOMON, B and RUEDI, A (2009). Full dynamic range proteome analysis of $S$. cerevisiae by targeted proteomics. Cell, 138: 795-806.

POST-BEITTENMILLER, D; ROUGHAN, G and OHLROGGE, J B (1992). Regulation of plant fatty acid biosynthesis: analysis of acyl-coenzyme a and acyl-acyl carrier protein substrate pools in spinach and pea chloroplasts. Plant Physiol, 100: 923-930.

PROC, J L; KUZYK, M A; HARDIE, D B; YANG, J; SMITH, D S; JACKSON, A M; PARKER, C E and BORCHERS, C H (2010). A quantitative study of the effects of chaotropic agents, surfactants, and solvents on the digestion efficiency of human plasma proteins by trypsin. J. Proteome Research, 9: 5422-5437.

RAMLI, U S; BAKER, D S; QUANT, P A and HARWOOD, J L (2002a). Control analysis of lipid biosynthesis in tissue cultures from oil crops shows that flux control is shared between fatty acid synthesis and lipid assembly. Biochemical J., 364: 393401.

RAMLI, U S; BAKER, D S; QUANT, P A and HARWOOD, J L (2002b). Control mechanisms operating for lipid biosynthesis differ in oil-palm (Elaeis guineensis Jacq.) and olive (Olea europaea L.) callus cultures. Biochemical J., 364: 385-391.

ROESLER, K; SHINTANI, D; SAVAGE, L; BODDUPALLI, $S$ and OHLROGGE, J (1997). Targeting of the Arabidopsis homomeric acetylcoenzyme A carboxylase to plastids of rapeseeds. Plant Physiol, 113: 75-81.

ROESSLER, P G (1990). Purification and characterization of acetyl-CoA carboxylase from the diatom Cyclotella cryptica. Plant Physiol, 92: 73-78.

SAMBANTHAMURTHI, R; ABRIZAH, O and RAMLI, U S (1999). Biochemical factors that control oil composition in the oil palm. J. Oil Palm Res. Special Issue: 24-33.

SASAKI, Y and NAGANO, Y (2004). Plant acetylCoA carboxylase: structure, biosynthesis, regulation, and gene manipulation for plant breeding. Biosci Biotechnol Biochem, 68: 1175-1184.

SCHUCH, R; WINTER, E; BRÜCK, F M; BRUMMEL, $\mathrm{M}$ and SPENER, F (1997). $\beta$-Ketoacyl-acyl carrier protein synthases in the regulation of fatty acid synthase activity in higher plants - an overview. Fett/Lipid, 99: 278-281.

SCHULTZ, D and OHLROGGE, J B (2001). Metabolic engineering of fatty acid biosynthesis. Lipid Biotechnology (Kuo, T M and Gardner eds.). Marcel Dekker Inc., New York.

SHINTANI, D K and OHLROGGE, J B (1995). Feedback inhibition of fatty acid synthesis in tobacco suspension cells. The Plant Journal, 7: 577-587. 
SINGH, R; LOW, E-T L; OOI, L C-L; ONGABDULLAH, M; TING, N-C; NAGAPPAN, J; NOOKIAH, R; AMIRUDDIN, M D; ROSLI, R; MANAF, M A A; CHAN, K-L; HALIM, M A; AZIZI, N; LAKEY, N; SMITH, S W; BUDIMAN, M A; HOGAN, M; BACHER, B; VAN BRUNT, A; WANG, C; ORDWAY, J M; SAMBANTHAMURTHI, R and MARTIENSSEN, R A (2013a). The oil palm SHELL gene controls oil yield and encodes a homologue of SEEDSTICK. Nature, 500: 340-344.

SINGH, R; ONG-ABDULLAH, M; LOW, E T; MANAF, M A; ROSLI, R; NOOKIAH, R; OOI, L C; OOI, S E; CHAN, K L; HALIM, M A; AZIZI, $\mathrm{N}$; NAGAPPAN, J; BACHER, B; LAKEY, N; SMITH, S W; HE, D; HOGAN, M; BUDIMAN, M A; LEE, E K; DESALLE, R; KUDRNA, D; GOICOECHEA, J L; WING, R A; WILSON, R K; FULTON, R S; ORDWAY, J M; MARTIENSSEN, R A and SAMBANTHAMURTHI, R (2013b). Oil palm genome sequence reveals divergence of interfertile species in Old and New worlds. Nature, 500:335-359.

STUMPF, P K (1969). Metabolism of fatty acids. Annu Rev Biochem, 38: 159-212.

SUNDRAM, K (2000). Chemistry and biochemistry of palm oil. Progress in Lipid Research, 39: 507-558.

SUNDRAM, K; SAMBANTHAMURTHI, $\mathrm{R}$ and TAN, Y A (2003). Palm fruit chemistry and nutrition. Asia Pac J Clin Nutr, 12: 355-362.

THELEN, J J and OHLROGGE, J B (2002a). Metabolic engineering of fatty acid biosynthesis in plants. Metab Eng, 4: 12-21.

THELEN, J J and OHLROGGE, J B (2002b). The multisubunit acetyl-CoA carboxylase is strongly associated with the chloroplast envelope through non-ionic interactions to the carboxyltransferase subunits. Archives of Biochemistry and Biophysics, 400: 245-257.

TRANBARGER, T J; DUSSERT, S; JOET, T; ARGOUT, X; SUMMO, M; CHAMPION, A; CROS, D; OMORE, A; NOUY, B and MORCILLO, F (2011). Regulatory mechanisms underlying oil palm fruit mesocarp maturation, ripening, and functional specialization in lipid and carotenoid metabolism. Plant Physiol, 156: $564-584$.

TRONCOSO-PONCE, $\mathrm{M}$ A; GARCÉS, $\mathrm{R}$ and MARTÍNEZ-FORCE, E (2010). Glycolytic enzymatic activities in developing seeds involved in the differences between standard and low oil content sunflowers (Helianthus annuus L.). Plant Physiology and Biochemistry, 48: 961-965.

WANG, Y-Q; YANG, Y; FEI, Z; YUAN, H; FISH, T; THANNHAUSER, T W; MAZOUREK, M; KOCHIAN, L V; WANG, X and LI, L (2013). Proteomic analysis of chromoplasts from six crop species reveals insights into chromoplast function and development. J. Experimental Botany, 64: 949961.

WIENKOOP, S and WECKWERTH, W (2006). Relative and absolute quantitative shotgun proteomics: targeting low-abundance proteins in Arabidopsis thaliana. J. Experimental Botany, 57: 15291535.

ZULAK, K G; LIPPERT, D N; KUZYK, M A; DOMANSKI, D; CHOU, T; BORCHERS, C H and BOHLMANN, J (2009). Targeted proteomics using selected reaction monitoring reveals the induction of specific terpene synthases in a multi-level study of methyl jasmonate-treated Norway spruce (Picea abies). The Plant Journal, 60: 1015-1030. 